\title{
Imaging a neglected transradial, trans-scaphoid volar perilunate fracture dislocation in a skeletally mature adult: a novel constellation
}

\author{
Sandeep Kumar, ${ }^{1}$ Anurag Ayachit, ${ }^{2}$ Mugil Varman, ${ }^{1}$ Satish Babu Maddukuri ${ }^{1}$
}

${ }^{1}$ Department of

Radiodiagnosis, Kasturba Medical College, Manipal, Karnataka, India

${ }^{2}$ Department of Radiology, Kasturba Medical College, Manipal, Karnataka, India

\section{Correspondence to} Dr Sandeep Kumar, drsandeepkumarradiologist@ gmail.com

Accepted 20 January 2015
CrossMark

To cite: Kumar $S$, Ayachit A, Varman $M$, et al. BMJ Case Rep Published online: [please include Day Month Year] doi:10.1136/ bcr-2014-208578

\section{DESCRIPTION}

A well-built 31-year-old man presented with deformity and restricted movements of the left wrist joint. He gave a history of injury due to a fall 8 months earlier, for which he was initially treated with a wrist slab for 3 months. Clinical examination revealed palmar flexion deformity with restricted movements in all directions at the left wrist joint. Neurovascular examination was unremarkable.

Plain film radiograph showed diffuse osteopaenia, overlapping of the two carpal rows, distracted fractures of radial styloid process and scaphoid with associated midcarpal volar dislocation (figure 1A, B). CT scan demonstrated a fracture across the waist of scaphoid with volar displacement of the distal scaphoid fracture fragment along with the distal row carpus (figure 2A). The lunate showed mild volar tilt but was adequately aligned with the radial articular surface, while capitate along with distal scaphoid fragment was dislocated volarly (figure $2 \mathrm{~B}$ ). The distal carpal row bones were well aligned with each other and showed maintained distal articulations with the metacarpal heads (figure 2C). Features of midcarpal osteoarthritic changes were also seen (figure 2D). Three-dimensional (3D) CT scan reconstruction demonstrated the maintained alignment between the individual carpi of the proximal and distal carpal rows with fractured proximal fragment of scaphoid remaining with the rest of proximal row carpi and its distal fragment moving anteriorly in concert with the volarly dislocated distal carpal row (figure 3A-C).

Perilunate fracture dislocation (PLD) occurs due to high-energy wrist hyperextension trauma and represents a common form of carpal dislocation. Usually, the carpus dislocates dorsally, but in 3\% it dislocates volarly. ${ }^{1}$ The functional anatomy of the wrist is best explained by Gilula's concept of three arcs, with the first arc formed by the proximal surfaces of scaphoid, lunate and triquetrum, the second arc formed by their corresponding distal articulating surfaces and the third arc formed by proximal curvature of capitate and hamate. ${ }^{2}$ Thus, effectively, the proximal carpal row forms an intercalated system between the radial articular surface and the distal carpal row, while scaphoid forms the stabilising link between the proximal and distal carpal rows. This arrangement of the carpus along with the intrinsic and extrinsic ligaments of the wrist provide stability to the wrist joint and also

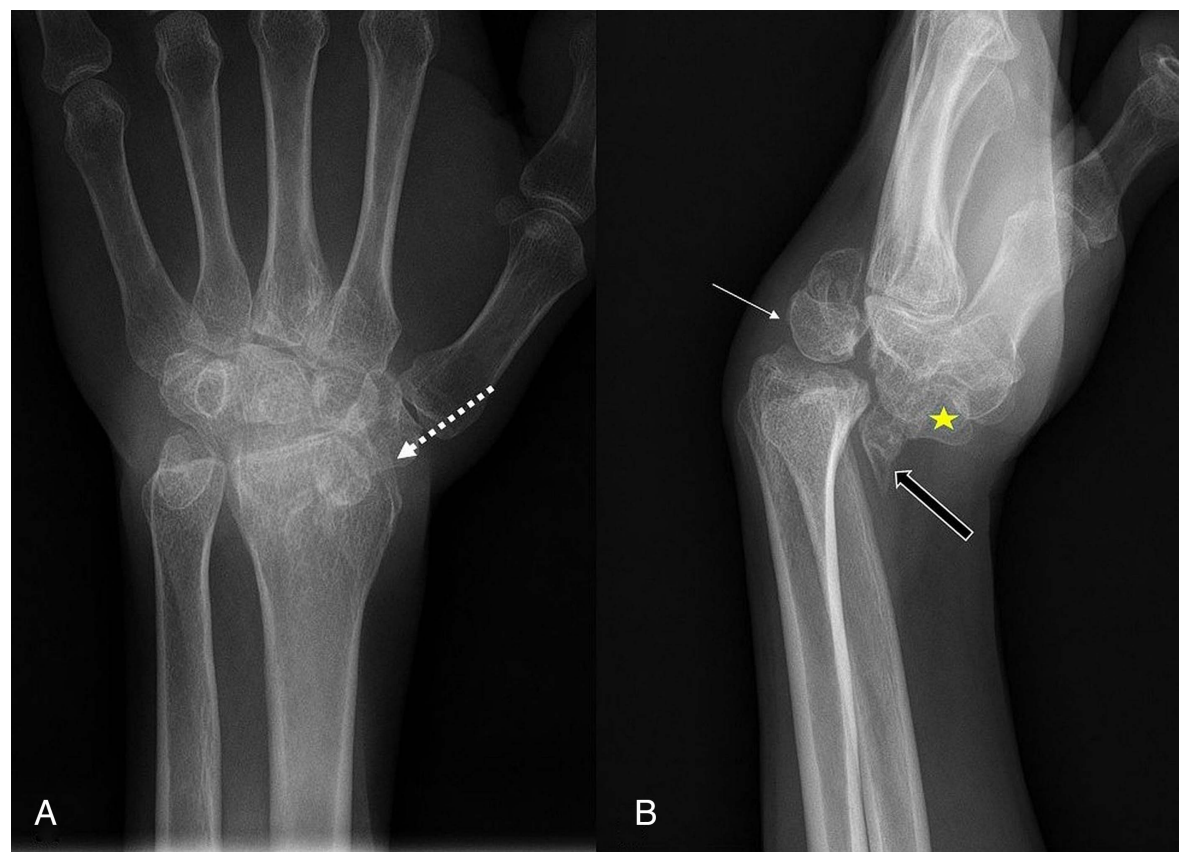

Figure 1 Radiograph of left wrist joint: Posteroanterior view (A) reveals diffuse osteopaenia and overlapping of the two carpal rows, with fractures of radial styloid process (dashed arrow) and scaphoid. Lateral view (B) reveals relative alignment of lunate (arrow) with the distal radial articular surface with volar dislocation of the distal carpal row. The avulsed fracture fragment of radial styloid is seen lying anteroinferiorly (black arrow) along with distal fractured fragment of scaphoid (yellow star). 


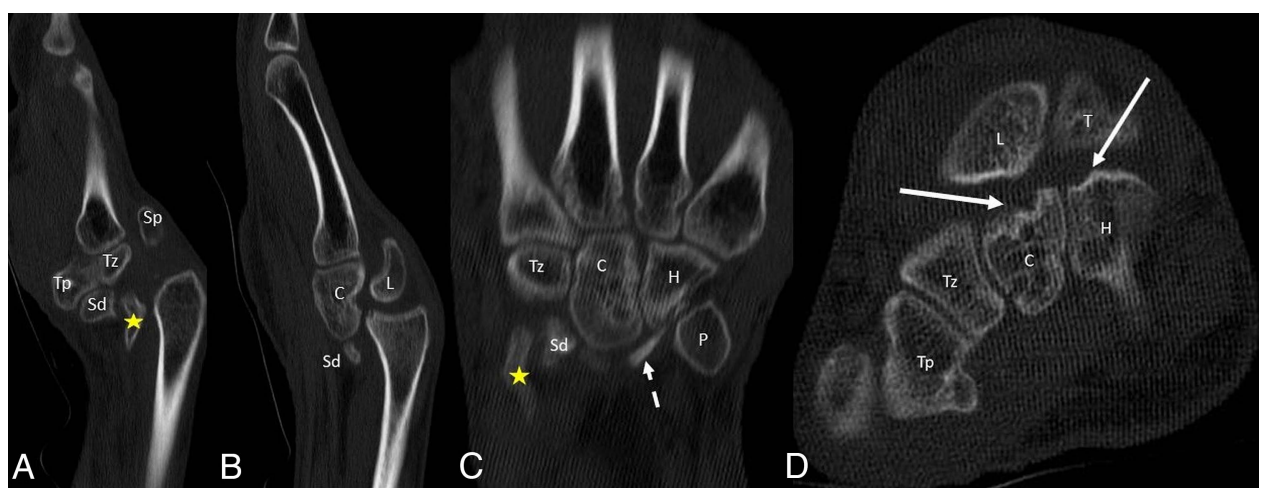

Figure 2 CT scan of left wrist joint: Sagittal image (A and B) shows distracted fracture across the waist of scaphoid with its proximal fragment $(\mathrm{Sp})$ and the mildly volarly tilted lunate (L) lying in relative alignment with the distal radius while the distal scaphoid fracture fragment (Sd) and the distal row carpi dislocated volarly. Coronal image (C) shows the normal alignment of distal carpal row bones among themselves and with their respective metacarpal articulations, highlighting their dislocation as a single unit. A small bone fragment was seen lying at the level of proximal articular surface of hamate (dashed arrow). Axial image (D) shows midcarpal osteoarthritic changes in the form of cortical irregularity, and sclerosis at articular surfaces of capitate and hamate (white arrow). Sp, proximal fractured fragment of scaphoid; Sd, distal fractured fragment of scaphoid; L, lunate; C, capitate; $H$, hamate; Tp, trapezium; Tz, trapezoid, T, triquetrum; (yellow star), avulsed fragment of radial styloid.

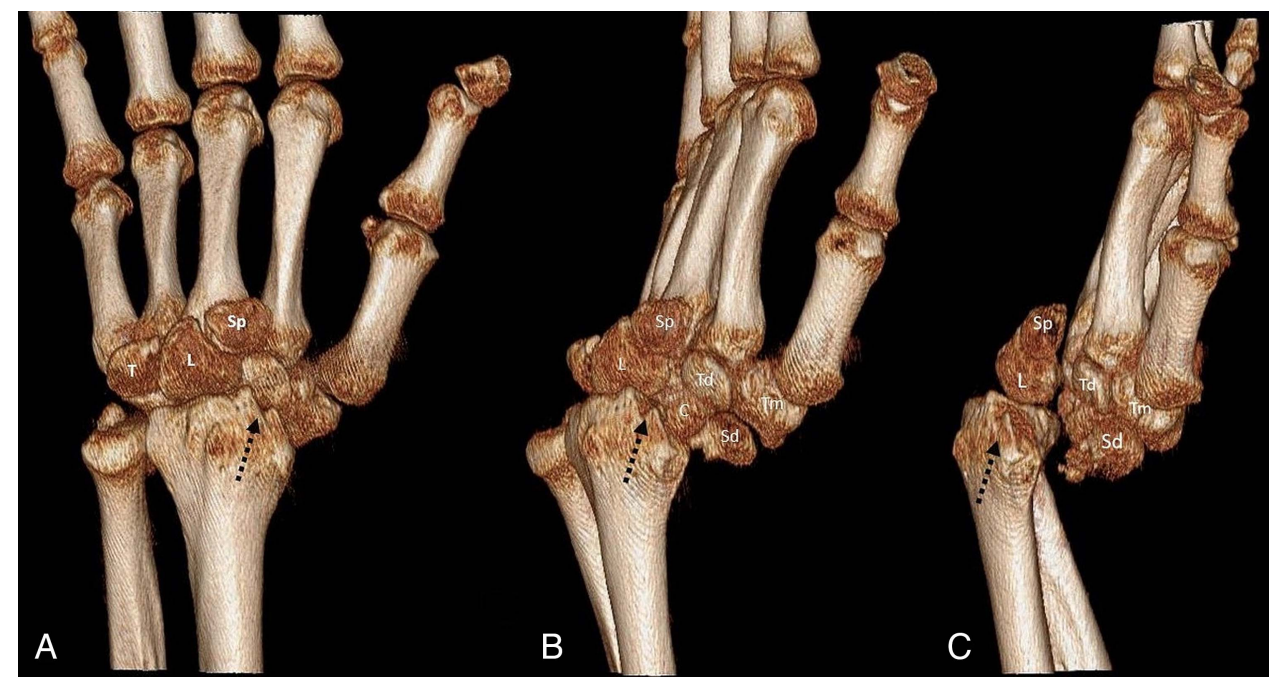

Figure 3 (A-C) Three-dimensional CT reconstruction images of the left wrist show features consistent with trans-styloid, trans-scaphoid volar perilunate fracture dislocation. Sp, proximal fractured fragment of scaphoid; Sd, distal fractured fragment of scaphoid; $L$, lunate; $C$, capitate; $H$, hamate; Tm, trapezium; Td, trapezoid; T, triquetrum; (dashed arrow), fracture of radial styloid.

form the basis for various fracture dislocation patterns at the wrist.

Classically, in trans-scaphoid PLD, the fractured proximal pole of scaphoid remains in alignment with lunate while the distal fragment dislocates dorsally along with the capitate but, unique to our case, this dislocation is seen volarly.

Almost $25 \%$ of perilunate dislocations are missed at initial examination, and their delayed presentation portends poorer prognosis, because open reduction and internal fixation have a better outcome in early post traumatic period as compared to neglected cases presenting after 6 weeks of trauma. ${ }^{13}$ CT scan with $3 \mathrm{D}$ reconstruction provides accurate assessment of the fracture dislocation, and provides an ideal roadmap for further management decisions. In the present case, the prognosis was deemed poor due to late presentation and secondary midcarpal osteoarthritis. The patient has been planned for two staged reduction surgery and presently is on follow-up, post spanning external fixator application. Nevertheless, the patient has been

\section{Learning points}

- Transradial, trans-scaphoid volar perilunate fracture dislocation represents a rare hyperextension injury of the wrist, characterised by complex midcarpal dislocation, having a fair chance of going unnoticed at initial examination, thus warranting a high index of suspicion.

- Imaging features are quite characteristic for this condition and CT scan plays an important role in accurately delineating the type and extent of fractures and dislocation, thus providing a road map for its surgical management.

- Open reduction and internal fixation is the treatment of choice in such cases in acute trauma settings, but in neglected cases, salvage procedures such as arthrodesis and proximal row carpectomy may be the only viable options. 
told that he might need salvage procedures such as proximal row carpectomy or arthrodesis later on.

This appearance of transradial, trans-scaphoid volar perilunate fracture in a skeletally mature individual presenting after 8 months of injury has not yet been documented in the literature. This case highlights the need for a high index of suspicion and awareness of the imaging findings for early recognition and prompt management of this disease entity.

Acknowledgements The authors would like to acknowledge the constant support and encouragement from Dr Rajagopal KV in preparing this manuscript.

Contributors SK diagnosed the condition and conceptualised the idea of the manuscript, and all the authors contributed to the design, literature search and final editing of the manuscript.
Competing interests None.

Patient consent Obtained.

Provenance and peer review Not commissioned; externally peer reviewed.

\section{REFERENCES}

1 Herzberg G, Comtet JJ, Linscheid RL, et al. Perilunate dislocations and fracturedislocations: a multicenter study. J Hand Surg Am 1993;18:768-79.

2 Gilula LA. Carpal injuries: analytic approach and case exercises. AJR Am J Roentgenol 1979;133:503-17.

3 Garg B, Goyal T, Kotwal PP. Staged reduction of neglected transscaphoid perilunate fracture dislocation: a report of 16 cases. J Orthop Surg Res 2012;7:19.

Copyright 2015 BMJ Publishing Group. All rights reserved. For permission to reuse any of this content visit http://group.bmj.com/group/rights-licensing/permissions.

BMJ Case Report Fellows may re-use this article for personal use and teaching without any further permission.

Become a Fellow of BMJ Case Reports today and you can:

- Submit as many cases as you like

- Enjoy fast sympathetic peer review and rapid publication of accepted articles

- Access all the published articles

- Re-use any of the published material for personal use and teaching without further permission

For information on Institutional Fellowships contact consortiasales@bmjgroup.com

Visit casereports.bmj.com for more articles like this and to become a Fellow 